\title{
Secondary hyperalgesia is not affected by wound infiltration with bupivacaine
}

The purpose of this study was to determine the effects of wound infiltration with bupivacaine on incisional pain and the zone of secondary hyperalgesia. Twenty-eight healthy parturients were studied in a double-blind randomized trial. At the time of Caesarean section one wound edge was infiltrated with saline $0.9 \%$ and the other with bupivacaine $0.25 \%$. After $24 \mathrm{hr}$, visual analogue scores were obtained for incisional pain and the zone of secondary pain around the incision was measured. Patients served as their own controls. Visual analogue scores for the bupivacaine side of the wound were less than for the saline side $(P<0.05)$. The zone of secondary pain was similar overall for both sides of the wound. It is concluded that the bupwacaine-infiltrated side of the wound was less painful than the saline-injected side $24 \mathrm{hr}$ posioperatively. The zone of pain measured around the wound edges was unaffected by bupivacaine or saline.

Cette étude vise à évaluer l'efficacité de lïnfiltration locale de bupivacaïne sur la douleur de lincision et la zone d'hyperalgie secondaire périphérique. Vingt-huit parturientes en bonne santé font partie de cette étude randomisée et à double insu. Au moment de la césarienne, une lèvre de la plaie est infiltrée avec du soluté physiologique $0,9 \%$ et l'autre avec de la bupivacaïne $0.25 \%$. Après 24 heures, on évalue sur une échelle visualle analogue la douleur de lincision et la zone d'hyperalgie secondaire périphérique, les patientes étant leurs propres contrôles. Les scores de léchelle visuelle analogue pour le côté

\section{Key words}

ANALGESIA: measurement;

ANAESTHETICS, LOCAL: bupivacaine;

PAIN: measurement, hyperalgesia.

From the Department of Anesthesiology* and Department of Obstetrics and Gynecology, $\uparrow$ University of South Florida

College of Medicine, Tampa, Florida.

Address correspondence and reprint requests to: Editorial

Office, Department of Anesthesiology, University of South

Florida College of Medicine, MDC Box 59, 12901 Bruce B.

Downs Blvd., Tampa, Florida, 33612-4799; telephone (813)

251-7438; FAX: (813) 251-7418.

Accepted for publication 29th July, 1993. bupivacaïne de la plaie sont plus bas que ceux du côté soluté physiologique $(P<0,05)$. La zone dhyperalgie secondaire est la même sur les deux côtés de la plaie. En conclusion, à la période postopératoire, le côté de la plaie infiltré avec la bupivacaïne est moins douloureux que le côté infiltré avec du physiologique. La zone de douleur mesurée en périphérie de la plaie n'est affectée ni par la bupivacaïne, ni par le physiologique.

Postoperative pain control remains a considerable problem despite recent advances in analgesia technology. ${ }^{1-4}$ Further progress will depend on a more effective application of existing techniques and a better understanding of acute pain physiology. Clinical investigations evaluating postoperative pain after inguinal herniorrhaphy, cholecystectomy and other operations have documented the phenomenon of prolonged postoperative pain relief after wound infiltration with local anaesthetics. ${ }^{5-8} \mathrm{~A}$ considerable decrease in incisional discomfort and opioid use for up to three days was noted when wounds were infiltrated with bupivacaine or lidocaine prior to closure.

The mechanisms underlying these clinical observations are unknown but three phenomena may contribute. Acute pain processing begins with activation of peripheral nociceptors. Nociceptors may become conditioned or sensitized after injury, which results in a state of lowered pain threshold and primary hyperalgesia. ${ }^{9}$ Thus, within the injured area, stimuli that aren't normally painful, such as light touch, may evoke pain. A class of small fibre pain receptors, $\mathrm{C}$ polymodal nociceptors (CPMN), is thought to contribute to the development of primary hyperalgesia because they may become sensitized following injury.

Not all hyperalgesia can be explained by lowered firing thresholds of CPMNs sensitized after injury. Undamaged CPMNs in normal tissue near the wound site may also begin to signal pain. These uninjured CPMNs adjacent to injured tissue may become sensitized when exposed to products released from stimulated white cells and cut nociceptive axons. ${ }^{9-12}$ This phenomenon, known as secondary hyperalgesia, manifests as a zone of soreness, 
which develops around the wound in uninjured skin. Animal experiments have demonstrated decreased secondary hyperalgesia after infiltration of injury sites with local anaesthetic." $A$ decrease in the zone of secondary hyperalgesia after local anaesthetic infiltration suggests that recruitment of uninjured CPMNs was prevented, thus contributing to the sustained analgesia.

A third or perhaps concomitant explanation may involve decreased sensitization of dorsal horn nociceptive neurons that transmit pain information to the spinothalamic tract and the brain. Woolf $e t$ al. and Ejlersen present evidence that central mechanisms are important in post injury pain, and excessive dorsal horn responsiveness has been demonstrated for many pain states. ${ }^{8,10}$ If the mechanism for the effects of local anaesthetic is primarily central then secondary hyperalgesia could be unaffected by the local injection and the zones of soreness on both sides of the wound would be similar. Whether peripheral or central mechanisms predominate has not been established.

We undertook a double-blind study to evaluate Caesarean section wound infiltration with bupivacaine and to examine its effects on incisional pain and secondary hyperalgesia.

\section{Methods}

Institutional approval and patient written informed consent were obtained. Twenty-eight healthy parturients were enrolled in a double-blind, randomized study of incisional pain after Caesarean section. Demographic data including height, weight, age, and gravidity were recorded. All patients had lumbar epidural catheters placed for labour and delivery. Continuous infusions of $0.1 \%$ bupivacaine with $0.5 \mu \mathrm{g} \cdot \mathrm{ml}^{-1}$ sufentanil at $10-12 \mathrm{ml} \cdot \mathrm{hr}^{-1}$ were given for labour. A variable bolus volume of $0.25 \%$ bupivacaine was given to achieve an adequate sensory level for Caesarean delivery. At the time of surgical closure, wounds were infiltrated with two solutions. After randomized assignment, one edge of the incision was injected with $0.25 \%$ preservative-free bupivacaine $1 \mathrm{ml} \cdot \mathrm{cm}^{-1}$ and the other edge received $0.9 \%$ saline $1 \mathrm{ml} \cdot \mathrm{cm}^{-1}$. The surgeon was blinded to the content of the injectate. Patients served as their own controls.

Postoperatively, patients were placed on patientcontrolled analgesia (PCA) with morphine sulphate 1 $\mathrm{mg} \cdot \mathrm{q} 10 \mathrm{~min}$ prn until bowel function resumed. Analgesic use was recorded for $30 \mathrm{hr}$. At 24 to $30 \mathrm{hr}$ wounds were evaluated for sensitivity to pressure. The skin was marked horizontally at $2 \mathrm{~cm}$ intervals $0.25 \mathrm{~cm}$ from the wound edges. Pressure was applied by depressing the skin $0.5 \mathrm{~cm}$ on the marked intervals with a cotton tipped swab. Visual analogue scores (VAS) were obtained at each 2 $\mathrm{cm}$ interval along both wound margins. Patients chose

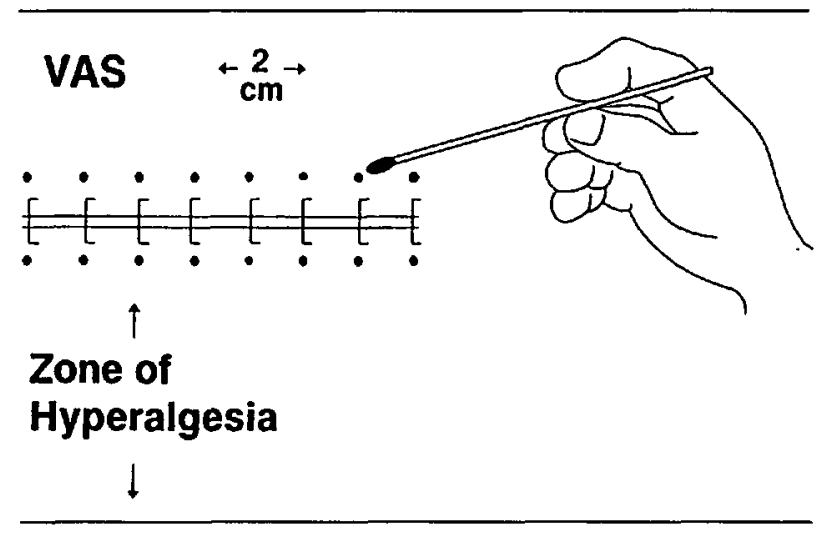

FIGURE 1 Visual analogue score measurement points along the wound at $2-\mathrm{cm}$ intervals. The zone of secondary pain in $\mathrm{cm}$ was measured perpendicular to the wound.

VAS scores for each of the pressure points tested on a scale of 0 to 10 , where 0 indicated no pain and 10 indicated the worst pain the patient could imagine. Evaluation of the test points on either side of the wound and along the axis of the wound was performed randomly. The investigator who obtained the pain scores was blinded to the injectate used.

A zone of painful sensation was measured away from each wound edge (Figure 1). As before, pressure was applied with the cotton tip swab at $2 \mathrm{~cm}$ intervals. This time the swab stimulus was moved out perpendicular to the incision to define the farthest distance, in centimeters, from the wound edge where the pressure stimulus was still perceived by the patient as painful. This measurement is described as the zone of secondary hyperalgesia. The VAS and zones of hyperalgesia were compared between the saline-injected side and the bupivacaine-injected sides. The data were summarized as mean $\pm S D$ and were analyzed with a paired Student's $t$ test.

\section{Results}

Twenty-eight ASA Class I or II patients were studied. The patients were $27 \pm 7 \mathrm{yr}$ old and weighed $76 \pm 18$ kg. Patients used $26 \pm 8 \mathrm{mg}$ (SD) PCA morphine sulfate postoperatively over $30 \mathrm{hr}$. There were 25 horizontal and three vertical incisions, all $\leq 16 \mathrm{~cm}$ in length. Three patients with vertical incisions and three patients with horizontal incisions were repeat Caesarean sections.

Patients served as their own controls and comparisons were made between the sides of the incision injected with saline and bupivacaine. The VAS were higher on the saline side at each $2 \mathrm{~cm}$ interval $24 \mathrm{hr}$ postoperatively $(P$ $<0.05$; Figure 2 ). Zones of secondary hyperalgesia did not differ between the saline and bupivacaine sides of the wounds $(P \leq 0.05)$, except at the 2 and $4 \mathrm{~cm}$ marks (Figure 3). There were no systemic or local complications of infiltration with either solution. 


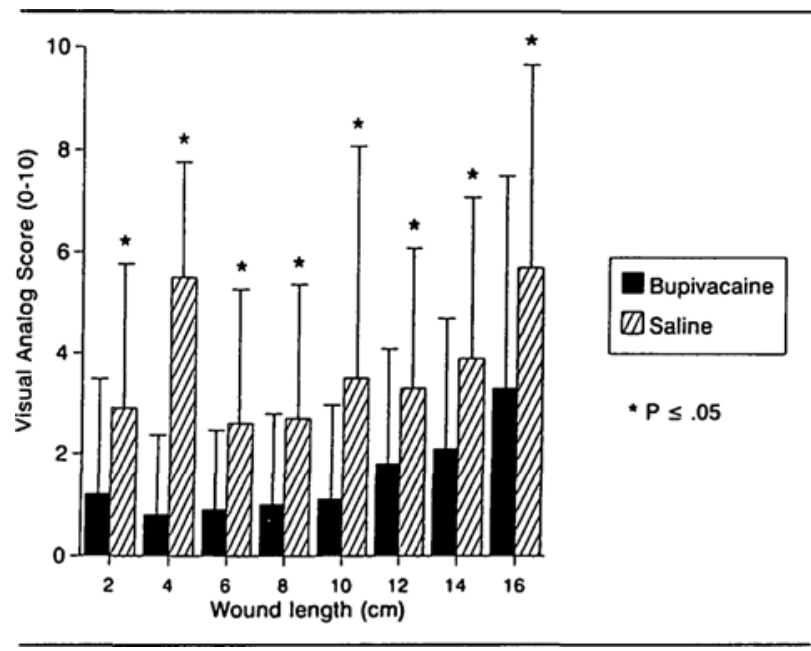

FIGURE 2 Mean visual analogue scores $(0-10)$ for incisional pain at $24 \mathrm{hr}$ postoperatively.

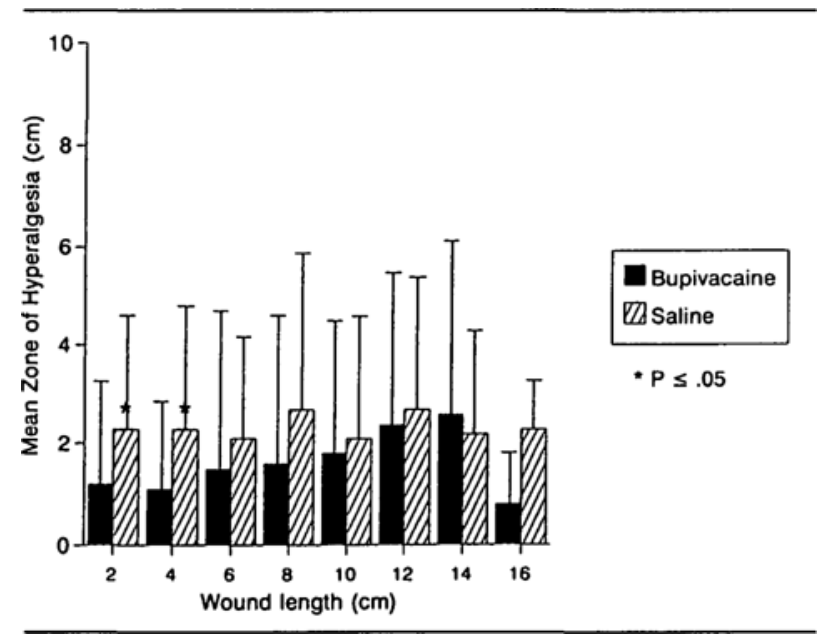

FIGURE 3 Mean zone of secondary hyperalgesia in $\mathrm{cm}$.

Thus, patients had more incisional pain on the salineinjected side of the wound than on the bupivacaine side. Overall, there was no difference between saline and bupivacaine in the zone of secondary pain away from the wound margins.

\section{Discussion}

We evaluated the effect of local anaesthetic infiltration on prolonged incisional analgesia. Incisional pain intensity on the bupivacaine-injected side was reduced for at least $24 \mathrm{hr}$. We sought to evaluate secondary hyperalgesia and found no difference in secondary hyperalgesia as a result of post-injury wound infiltration with bupivacaine.

Our data on the effects of local anaesthetic wound infiltration on postoperative analgesia are consistent with the findings of others. The visual analogue pain scores and modest postoperative PCA morphine use suggest a considerable and prolonged analgesic effect after local infiltration. The lack of change in secondary hyperalgesia differs from the findings of another study using animal models. This may be due to species differences and an experimental versus operative pain model.

Mechanisms to explain the diminution in incisional pain might include decreased primary nociceptor sensitization (primary hyperalgesia) or less concomitant activation of laminae 2 and 5 pain processing neurons in the dorsal horn. Our methods could not distinguish between the latter two effects. Patients served as their own controls and no evaluation of global pain scores, comparative narcotic use, etc., could be made.

A further confounding variable in our study was the effect of the epidural local and opiate on dorsal horn processing. It is possible that the epidural prevented sensitization of wide dynamic range neurons and thus offset the peripheral influence of local on sensitization of uninjured axons and secondary hyperalgesia. Thus the zone of secondary hyperalgesia was similar for both sides. However, the central effects of the epidural were not of a significant magnitude to impair detection of the decreases in primary hyperalgesia, which we noted for the bupivacaine side of the wound.

We failed to demonstrate any change in secondary hyperalgesia with post-injury bupivacaine infiltration of wounds. The effects of preinjury infiltration with local on secondary hyperalgesia are unknown. Preemptive pain control remains a desirable but elusive goal. Increased understanding of acute nociceptive processing will help us to prevent postoperative pain more effectively.

\section{Acknowledgements}

The authors would like to express their appreciation to Maura LeCroy and Valerie Fumea for editorial assistance.

\section{References}

1 Clinton JJ. Acute pain management can be improved. JAMA 1992; 267: 2580.

2 Lavies N, Hart L, Rounsefell B, Runciman W. Identification of patient, medical and nursing staff attitudes to postoperative opioid analgesia: stage 1 of a longitudinal study of postoperative analgesia. Pain 1992; 48: 313-9.

3 Winefield HR, Katsikitis $M$, Hart LM, Rounsefell BF. Postoperative pain experiences: relevant patient and staff attitudes. J Psychosom Res 1990; 34: 543-52.

4 Ready LB, Oden R, Chadwick HS, et al. Development of an anesthesiology-based postoperative pain management service. Anesthesiology 1988; 68: 100-6.

5 Patel JM, Lanzafame RJ, Williams JS, Mullen BV, Hinshaw $J R$. The effect of incisional infiltration of bupivacaine hydrochloride upon pulmonary functions, atelectasis 
and narcotic need following elective cholecystectomy. Surg Gynecol Obstet 1983; 157: 338-40.

6 Moss G, Regal ME, Lightig $L$. Reducing postoperative pain, narcotics, and length of hospitalization. Surgery 1986; 99: 206-10.

7 Tverskoy M, Cozacov C, Ayache M, Bradley EL, Kissin I. Postoperative pain after inguinal herniorrhaphy with different types of anesthesia. Anesth Analg 1990; 70: 29-35.

8 Ejlersen $E$, Andersen $H B$, Eliasen $K$, Mogensen $T$. A comparison between preincisional and postincisional lidocaine infiltration and postoperative pain. Anesth Analg 1992; 74 : 495-8.

9 Fields $H L$. Pain. New York: McGraw-Hill Information Services Company, 1987; 13-40.

10 Wall $P D$, Woolf $C J$. The brief and the prolonged facilitatory effects of unmyelinated afferent input on the rat spinal cord are independently influenced by peripheral nerve section. Neuroscience 1986; 17: 1199-205.

11 LaMotte $R H$. Can the sensitization of nociceptors account for hyperalgesia after skin injury? Human Neurobiology 1984; 3: 47-52.

12 Fitzgerald $M$. The spread of sensitization of polymodal nociceptors in the rabbit from nearby injury and by antidromic nerve stimulation. J Physiol 1979; 297: 207-16. 